\title{
Verzeichnis der Redner
}

Achterberg S. 133

Bachof S. 292, 299

Bettermann S. 275

Blümel S. 300

Brohm S. 127, 296

Bullinger S. 266

Delbrück S. 284

Denninger S. 268

Frowein S. 13, 114, 143

Häberle S. 298

Hellbling S. 302

Hettlage S. 99

Ipsen S. 128, 294

Kewenig S. 111

Kisker S. 122, 276

Lerche S. 87, 98, 111, 128, 131, 140, 145

Maurer S. 292

Mayer Franz S. 131, 288

Merten S. 277

v. Münch S. 51, 140

Mußgnug S. 137

Partsch S. 104, 139

Püttner S. 273

Rill S. 87

Roellecke S. 297

Rudolf S. 120

Rupp S. 266, 304, 312

Saladin S. 93

Scheuner S. 7

Schmitt Glaeser S. 179, 278, 304

Scupin S. 124

v. Simson S. 129

Soell S. 116, 136

Stern S. 106

v. Unruh S. 269

Walter S. 147, 282, 308

Wenger S. 134, 285

Winkler S. 290 
